This PDF is a selection from an out-of-print volume from the National Bureau of Economic Research

Volume Title: Aging Issues in the United States and Japan

Volume Author/Editor: Seiritsu Ogura, Toshiaki Tachibanaki and David A. Wise, editors

Volume Publisher: University of Chicago Press

Volume ISBN: 0-226-62081-6

Volume URL: http://www.nber.org/books/ogur01-1

Publication Date: January 2001

Chapter Title: Concentration and Persistence of Health Care Costs for the Aged

Chapter Author: Seiritsu Ogura, Reiko Suzuki

Chapter URL: http://www.nber.org/chapters/c10289

Chapter pages in book: (p. 187 - 222) 


\title{
Concentration and Persistence of Health Care Costs for the Aged
}

\author{
Seiritsu Ogura and Reiko Suzuki
}

\subsection{Introduction}

There have been very few studies of the distribution of health care costs among individuals in Japan. The most likely explanation for this may be an absence of the appropriate longitudinal data sets that are indispensable to carrying out such analyses. Another reason, however, may be the implicit assumption that health care resources naturally are consumed by a small number of individuals who are in poor health or are in danger of dying. Moreover, even if we find that health care expenditures indeed are heavily concentrated among a few individuals, is there anything to be done about it? Are we ready to look at total health care resources and decide anew how they should be distributed?

It is interesting to note that it is common to discuss the regional variation in health care costs, even in Japan. Regional variations have been studied jointly with the physician-induced demand (PID) hypothesis; in PID studies, generally speaking, the main objective was not to judge whether given regions were spending too little or too much, but rather to test a particular hypothesis about how health care expenditures are determined.

This paper describes the distribution of health care expenditures among the elderly in Japan. We examine both regional and interpersonal variations in the hope of finding what determines each. Some have argued that it is not appropriate for us to discuss the interpersonal distribution of health care resources, ${ }^{1}$ but we do not subscribe to such an "extreme" view.

Seiritsu Ogura is professor of economics at Hosei University. Reiko Suzuki is a senior economist at the Japan Center for Economic Research.

1. This is one of the reactions to a study on the costs of terminal care patients written by one of the coauthors of the present paper. 
Even if we cannot find a way to improve the distribution of health care right away, we may obtain new insights into what health care is really about, why it costs so much, and why it grows so persistently.

The rest of this paper is constructed as follows: In section 6.2, we outline the distribution of health care costs among the elderly population, and single out the factors that characterize the high-cost elderly. In section 6.3, we focus on the high-cost elderly as represented by long-term inpatients and look into the effect that long-term hospitalization has on the regional variation in health care costs.

\subsection{Distribution of Health Care Costs among the Japanese Elderly Population}

As we stated at the beginning of this paper, there is virtually no information on the distribution of medical costs among elderly individuals (seventy years old or over) in Japan. It is the primary purpose of our exposition here to present a reasonably accurate picture of the distribution of medical expenditures among such individuals. We then focus on the characteristics of the "expensive" elderly and try to single out the factors that make them expensive.

\subsubsection{Data Sources}

We use a subset of the experimental Health and Medical Services System for the Elderly (HMSSE) data collected by a group of researchers at the National Institute of Public Health. ${ }^{2}$ The original data were collected from participating municipalities of twelve prefectures during the period 1991-93. (Certain prefectures' data were ultimately excluded, as will be discussed later.) The original database consists of two different data sets: Part A provides a summary of the health insurance claims of individual elderly in each month of that year, and Part B provides a slightly more detailed accounting of health insurance claims in a given month of the year (cross-sectional data). As a basis of our analysis we have chosen samples that satisfy the following requirements:

Complete records for twenty-four months. We selected individuals with complete entries for each month in Part A for both 1992 and 1993, including months with zero claims. ${ }^{3}$ Some prefectures, such as Hokkaido, Osaka, and Kochi, use different identification codes for different years; we eliminated their data.

2. The group was headed by professor Atsushi Gunji of Tokyo University; Mr. Tetsuji Fukawa almost single-handedly collected and prepared the data.

3. Again, we have excluded those who have become eligible for HMSSE benefits or those who have died sometime in the course of these two years. 
Consistent identification coding for Part A and Part B. Unlike Part A, where the costs of all claims are aggregated for an individual, Part B contains the costs and primary diagnosis of each claim for one month in 1992 and 1993. Some municipalities (and all the municipalities in Okayama) used different identification codes for Part A and Part B, making it impossible to integrate them.

Matching 1993 for Part A and Part B. More municipalities provided Part B data in 1993 than in 1992. As a result, even in prefectures that used consistent identification codes for Part A and Part B and did so for both years, we have far more individuals matching in 1993 than in 1992. Instead of insisting that individual records match in 1992 and 1993, we require that they match only in 1993; we rely on 1993 diagnoses as our source of primary diagnosis.

Of the original data covering twelve prefectures, only data from Aomori, Fukushima, Toyama, Ishikawa, Fukui, Shizuoka, Shiga, and Wakayama met these criteria. So far, we have analyzed the data from Aomori, Fukushima, Toyama, Fukui, and Wakayama. Thus, our samples may not be nationally representative, because these five prefectures are concentrated heavily toward the rural north and are perhaps below average in terms of economic well-being. The number of individuals in our sample of five prefectures is 479,673 for Part A, ${ }^{4}$ and 328,134 for Part B.

\subsubsection{Individual Ranking of Health Care Expenditures}

We added inpatient and outpatient health care costs for each individual during the twenty-four-month period, ranked each individual in order of total expenditures within each prefecture, then computed the percentile for each individual in the prefecture. No attempt has been made to generalize percentiles across prefectures or to the general population. In the five prefectures taken together, the health care costs during these two years totaled 952,602 yen per elderly patient, ${ }^{5}$ of which 474,170 yen were for inpatient care and 478,432 yen were for outpatient care.

\subsubsection{Concentration of Health Care Expenditures}

In Japan as in the United States (Gornick, McMillan, and Lubitz 1993), at any point in time, health care expenditures are concentrated heavily on a relatively small number of individuals; this pattern tends to persist over

4. Of these, Aomori accounted for 110,323, Fukushima for 92,801, Toyama for 103,896, Fukui for 74,182 , and Wakayama for 98,471 .

5. The average total cost figure was 963,784 yen for Aomori, 855,449 yen for Fukushima, $1,101,504$ yen for Toyama, 933,319 yen for Fukui, and 899,052 yen for Wakayama. The average total inpatient-care cost figure was 497,161 yen for Aomori, 407,956 yen for Fukushima, 606,050 yen for Toyama, 468,959 yen for Fukui, and 375,614 yen for Wakayama. 
time. In our sample of almost half a million elderly in five prefectures observed over a two-year period, the median elderly spent slightly more than 500,000 yen in two years, while the mean elderly spent almost twice as much, slightly less than 1 million yen. The top 1 percent, on the other hand, spent about 9.5 million yen, or about twenty times the median amount, during the same period.

In terms of the proportion of the total expenditures on health care in a given prefecture, the results are even more dramatic. The bottom half of the elderly in terms of health care costs spent about 11 percent of the total, while the top 1 percent spent about 10 percent of the total. The top 3 percent spent about 22 percent of the total, the top 5 percent about 30 percent, and the top 10 percent about 45 percent. Now we know that, even among the elderly, health care expenditures are very heavily concentrated on a relatively small number of individuals. The degree of concentration is probably far beyond anything anyone has yet imagined.

\subsubsection{Inpatient Care Costs, Outpatient Care Costs, and the Factors Leading to Concentration}

In order to single out factors leading to this drastic concentration of health care expenditures, we decompose expenditures into inpatient and outpatient care costs. Figure 6.1 shows three cumulative distribution functions: for total costs, inpatient care costs, and outpatient care costs. The horizontal axis variable, the percentile ranking of health care costs, is common in three distributions. Clearly, compared with the distribution of total health care costs, outpatient costs are distributed far more equally among the elderly, and inpatient care costs are even more concentrated among the expensive few. In terms of the numbers, the bottom half of the elderly population consumed only about 1.2 percent of total inpatient care costs, but about 20 percent of total outpatient costs. The top 1 percent consumed about 3 percent of the total outpatient care costs, but almost 17 percent of the inpatient care costs. The top 10 percent consumed 18.4 percent of the outpatient care costs, but 73.5 percent of the inpatient care costs. Thus, it is the inpatient care costs that are producing the heavily concentrated health care expenditure patterns in the elderly population in Japan.

The two cumulative distributions in figure 6.2 look almost identical to those in figure 6.1, but are based on the number of days that health care services were received: the number of visits for outpatients and the number of days hospitalized for inpatients. Each distribution is shown separately in figures 6.3 and 6.4, respectively. Comparing these two, we may conclude that the primary determinant of the concentrated expenditure pattern is the extraordinarily large number of days that the highest percentile of elderly are hospitalized. For instance, not the proportion of individuals who stayed in the hospital for more than 730 days in each percentile of total health care costs. At the 95 th percentile, only 2 percent of the elderly 


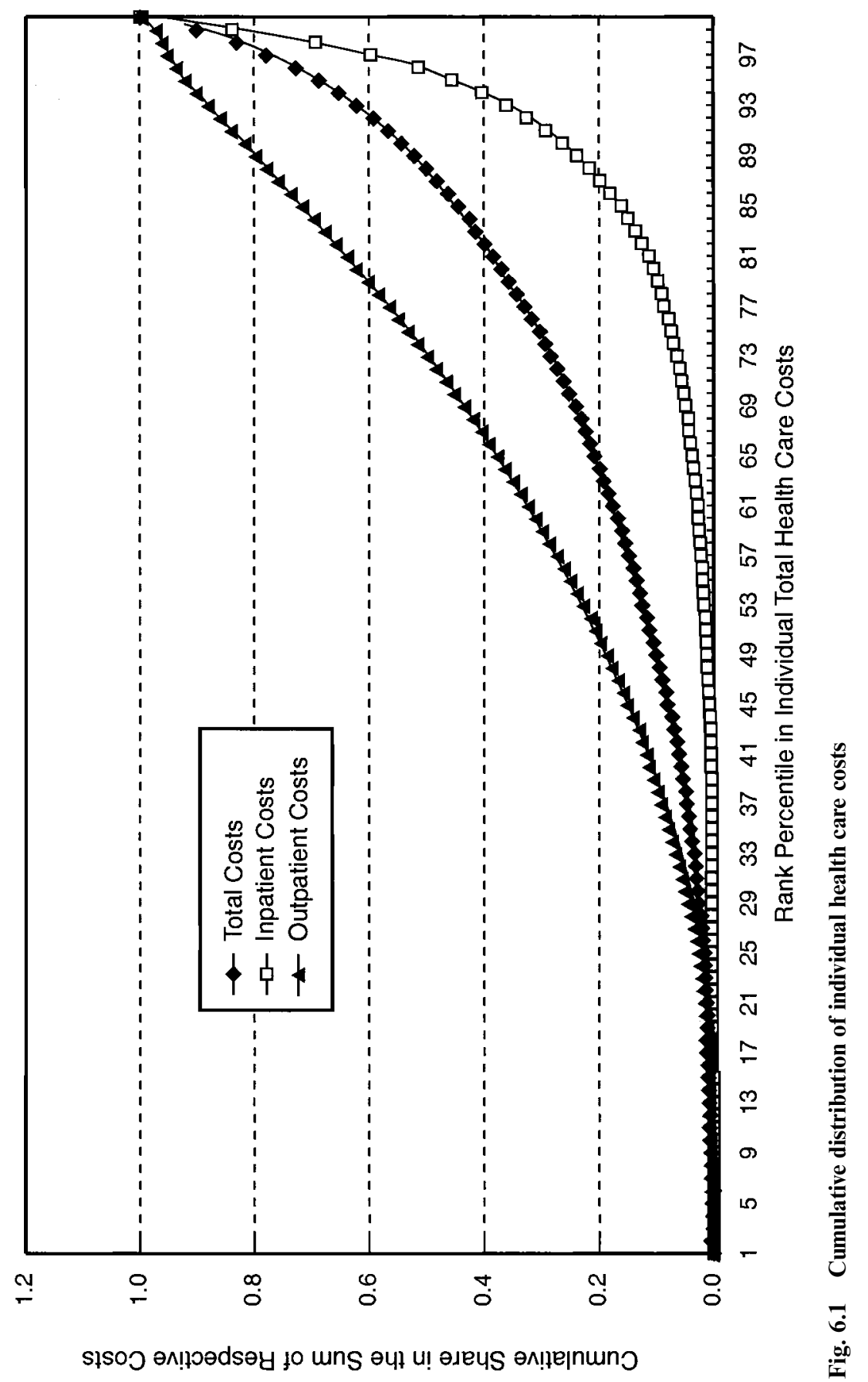




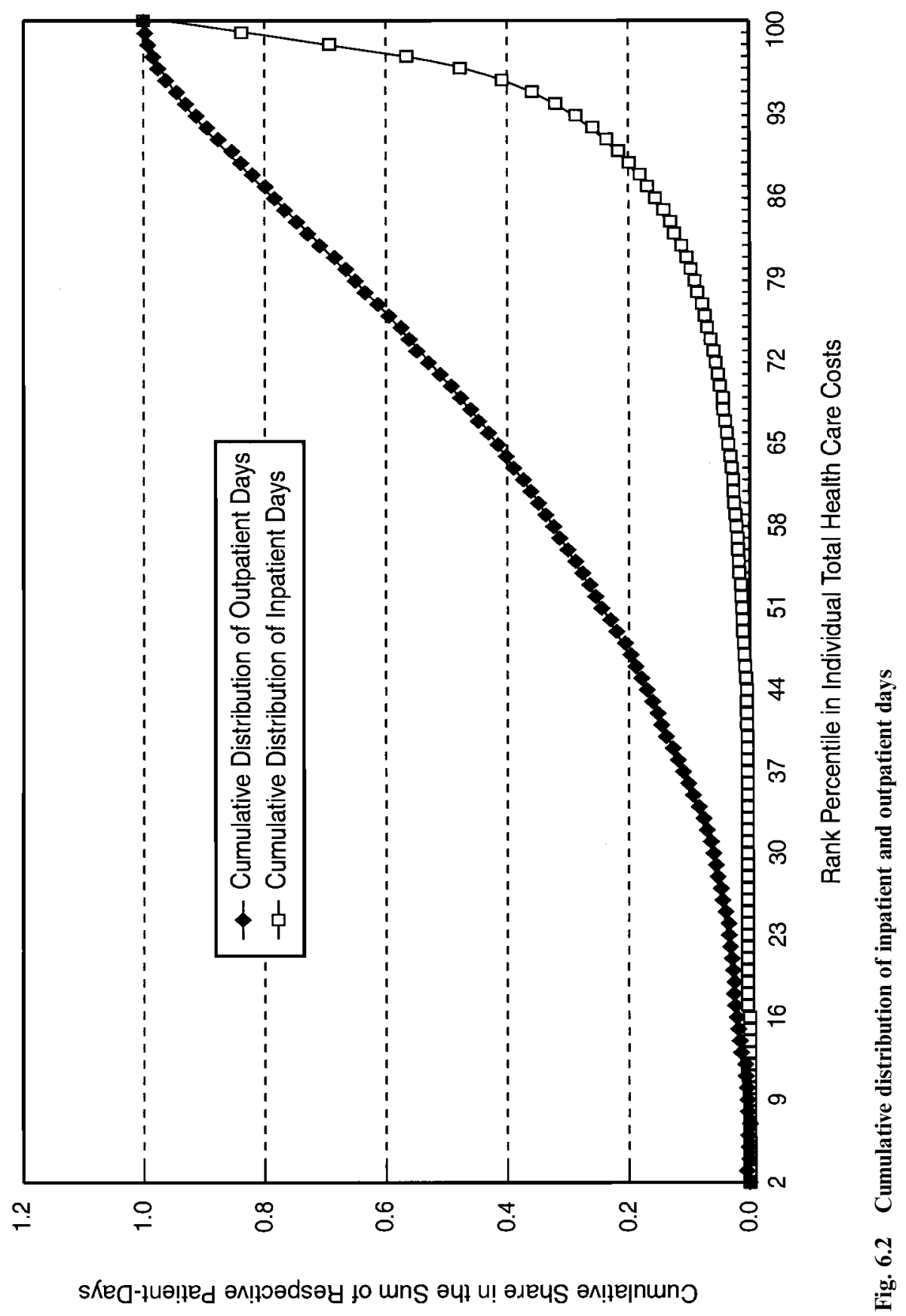




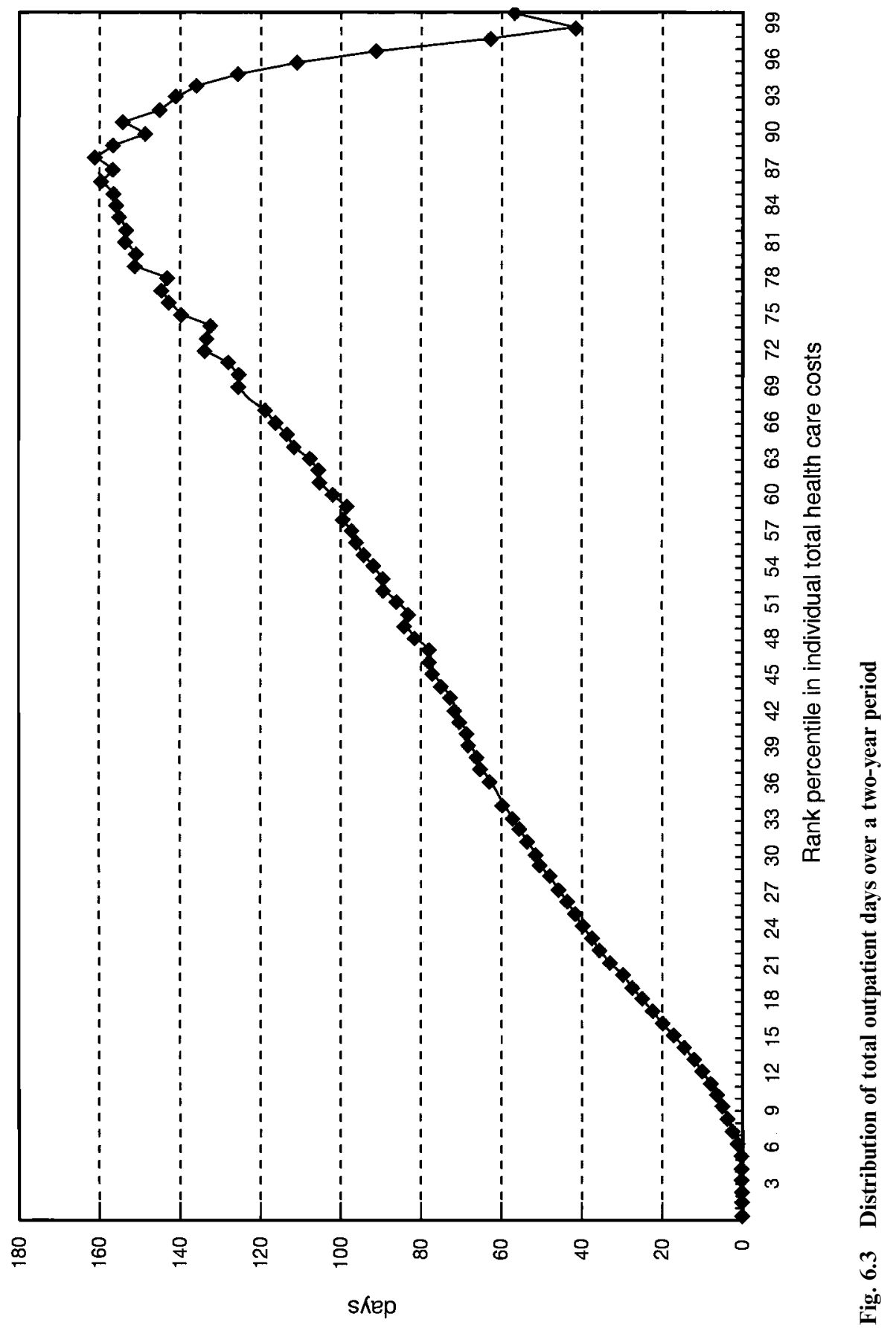




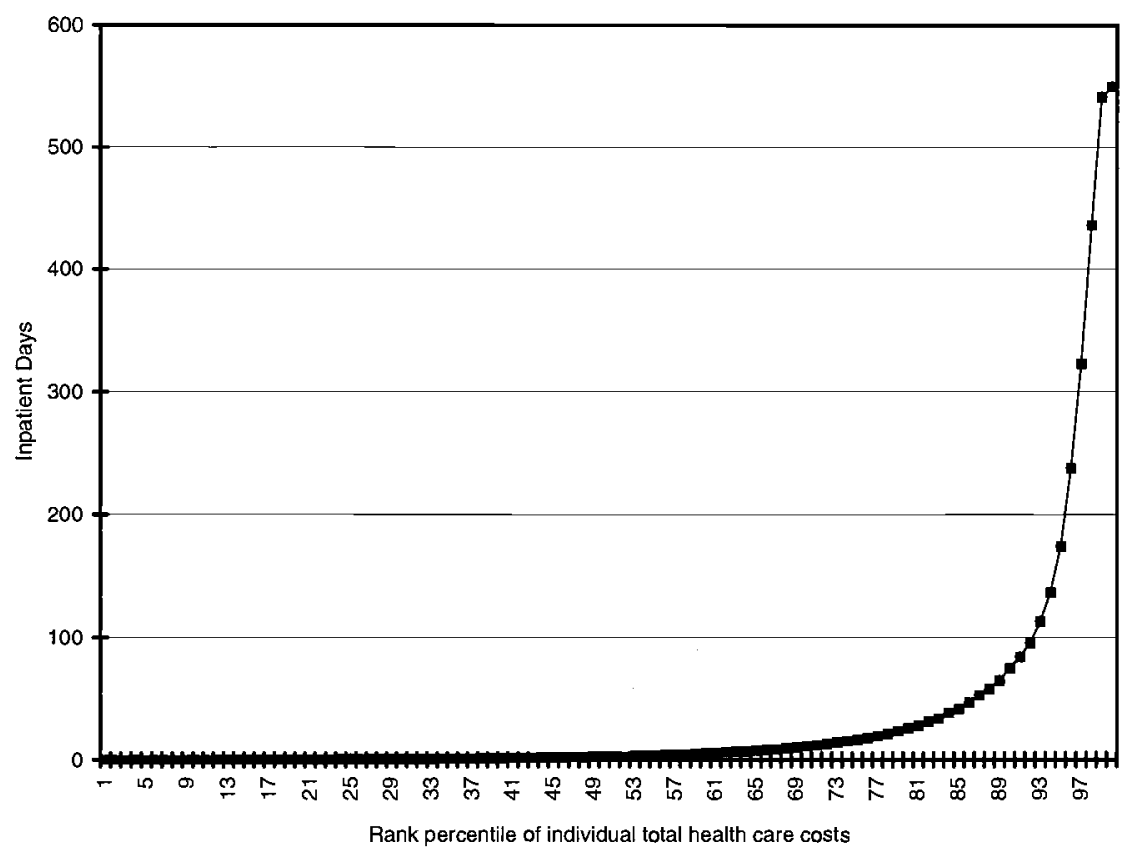

Fig. 6.4 Cumulative distribution of inpatient days

stayed in the hospital practically every day of the two-year period. At the 96th percentile, that proportion was 6 percent. But the proportion increases to 15 percent at the 97 th percentile, 27 percent at the 98 th percentile, 40 percent at the 99 th percentile, and 45 percent at the top 1 percent.

\subsubsection{Primary Diagnoses of the "Expensive Elderly"}

In order to obtain information on diagnoses of the patients in Part B, we integrated Part B (cross-sectional data) with Part A (longitudinal data) for each patient. There were two problems associated with this process. First, since not everyone receives medical care in a given month, we lost some individuals who were in Part A. In fact, we lost about one-fourth of the individuals in Part A in this process, including those who never see a doctor during these twenty-four months. We were still left with almost 330,000 individuals in our combined sample. Second, in a given month, many patients see several doctors for an identical (or different) ailment(s); these several doctors may in turn give different diagnoses. For these patients, we had to choose a primary diagnosis. We simply chose the diagnosis for the most expensive claim of each patient in the month.

Table 6.1 gives the distribution of primary diagnoses of the patients whose Part A and Part B records are successfully integrated. In the same table, the distribution of primary diagnoses of the top 3 percent in health 


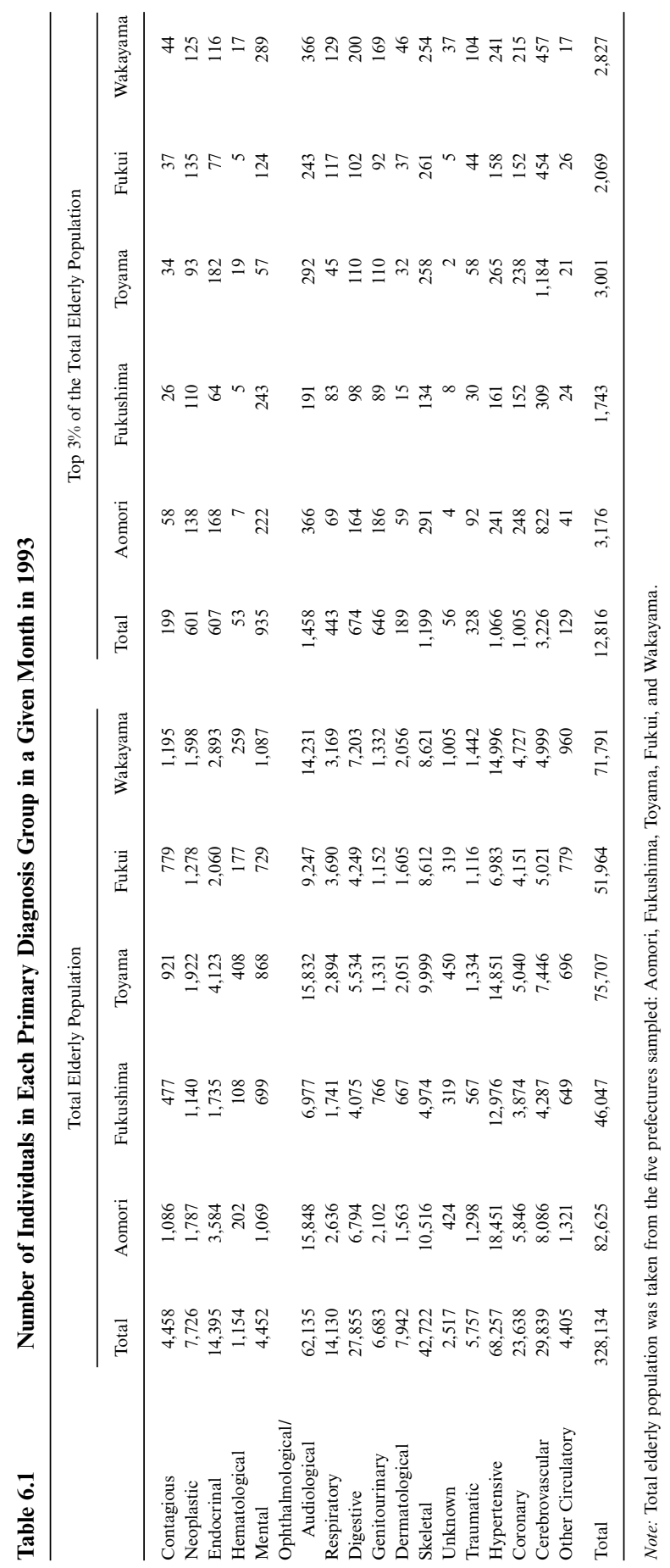


care costs are given. In the general population of elderly, the most common diagnosis is hypertension ( 20.8 percent), followed by ailments of the nervous system (18.9 percent) and the musculoskeletal system. Among the group we describe as the "expensive" elderly, however, it is cerebrovascular disease ( 25.2 percent), followed by mental disease (11.4 percent). We have also computed the probabilities that a patient in each primary diagnosis group will join the expensive elderly. ${ }^{6}$ Mental diseases rank the highest at 21.0 percent, or 7.0 times the average likelihood; cerebrovascular diseases rank second highest (10.8 percent); and diseases of the urinary system rank third highest (9.7 percent), or 3.0 times the average likelihood.

Tables 6.2 through 6.4 give the average total costs, average inpatient care costs, and average outpatient care costs, respectively. Table 6.5 computes how much more time the expensive elderly spend in inpatient and outpatient care than do the average elderly with the same primary diagnosis. On average, the expensive elderly consume about 10.8 times as much inpatient care as the average elderly, but only 1.3 times as much outpatient care. On the other hand, average patients with mental diseases, diseases of the urinary system, and cerebrovascular diseases are relatively expensive to begin with and consume relatively intensive inpatient care, which accounts for the relatively low numbers for these groups for inpatient care.

\subsubsection{Relevance of the Type of Medical Institution}

Part B provides some information on the type of medical institution where a patient has been treated. Unfortunately, the classification of medical institutions is very crude. It distinguishes a teaching hospital, an incorporated private hospital, a hospital that is neither teaching nor incorporated, a clinic, or an out-of-prefecture institution, but does not provide any information on the size or location of the institution.

Based on this limited information, we have computed distribution statistics for utilization and costs. Table 6.6 shows the distribution of elderly patients across different types of institutions in a given month of 1993 in each prefecture. Throughout the municipalities of these five prefectures, 57 percent of all patients chose clinics, 12 percent chose incorporated private hospitals, and 28 percent chose the other types of hospitals. Teaching hospitals and out-of-prefecture hospitals accounted for only 1 percent of patients each. As for the expensive elderly, the distributions are very different (table 6.7): Only 17 percent were in clinics, but 42 percent were in incorporated private hospitals, and 36 percent in the other types of hospitals. Thus, if one is computing the probability that a patient in a given type of institution belongs to the expensive elderly (table 6.8), incorporated pri-

6. As we have defined the "expensive" to be at the top 3 percent, if we sum over all the primary diagnosis groups, we should get 3 percent-but, in fact, we recovered 3.9 percent. This is due to the fact that top 3 percent are defined relative to all the elderly in Part A, from which we have lost about one-fourth in our attempt to combine Part A with Part B. 


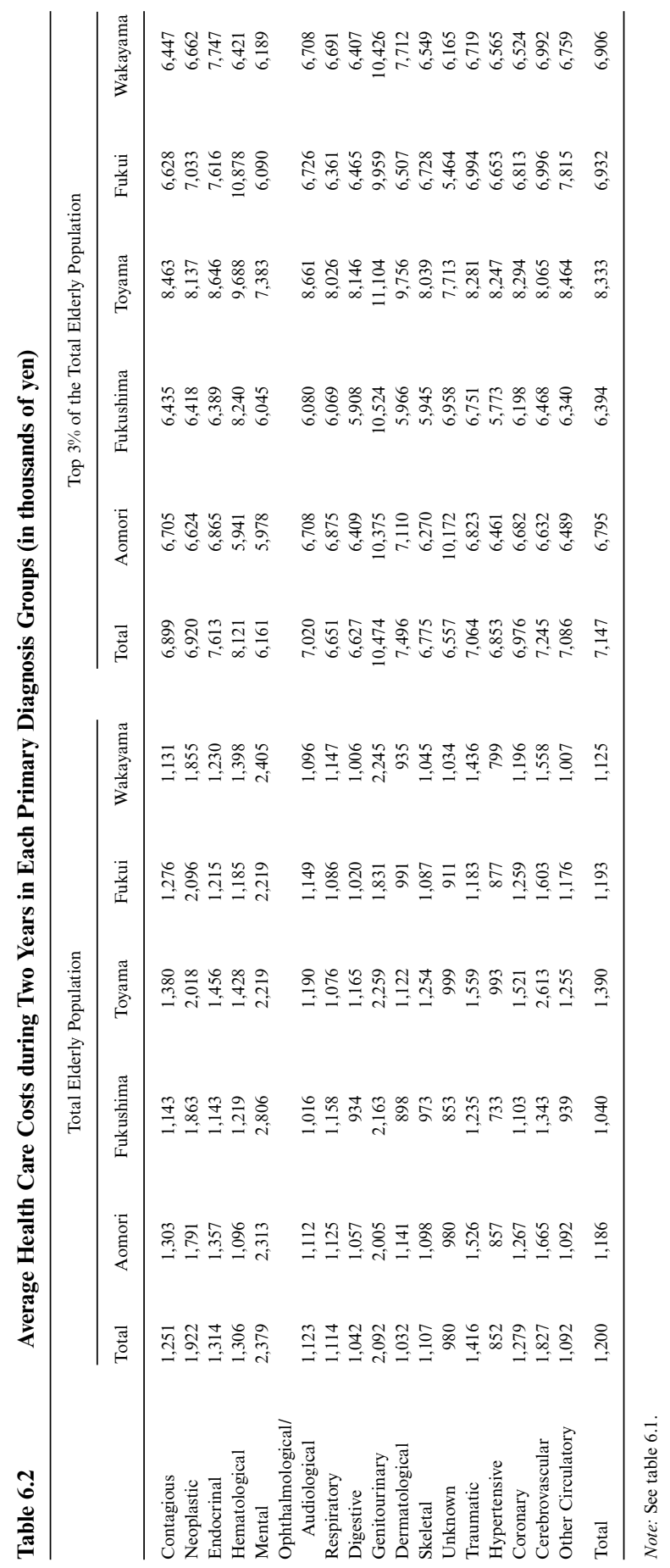




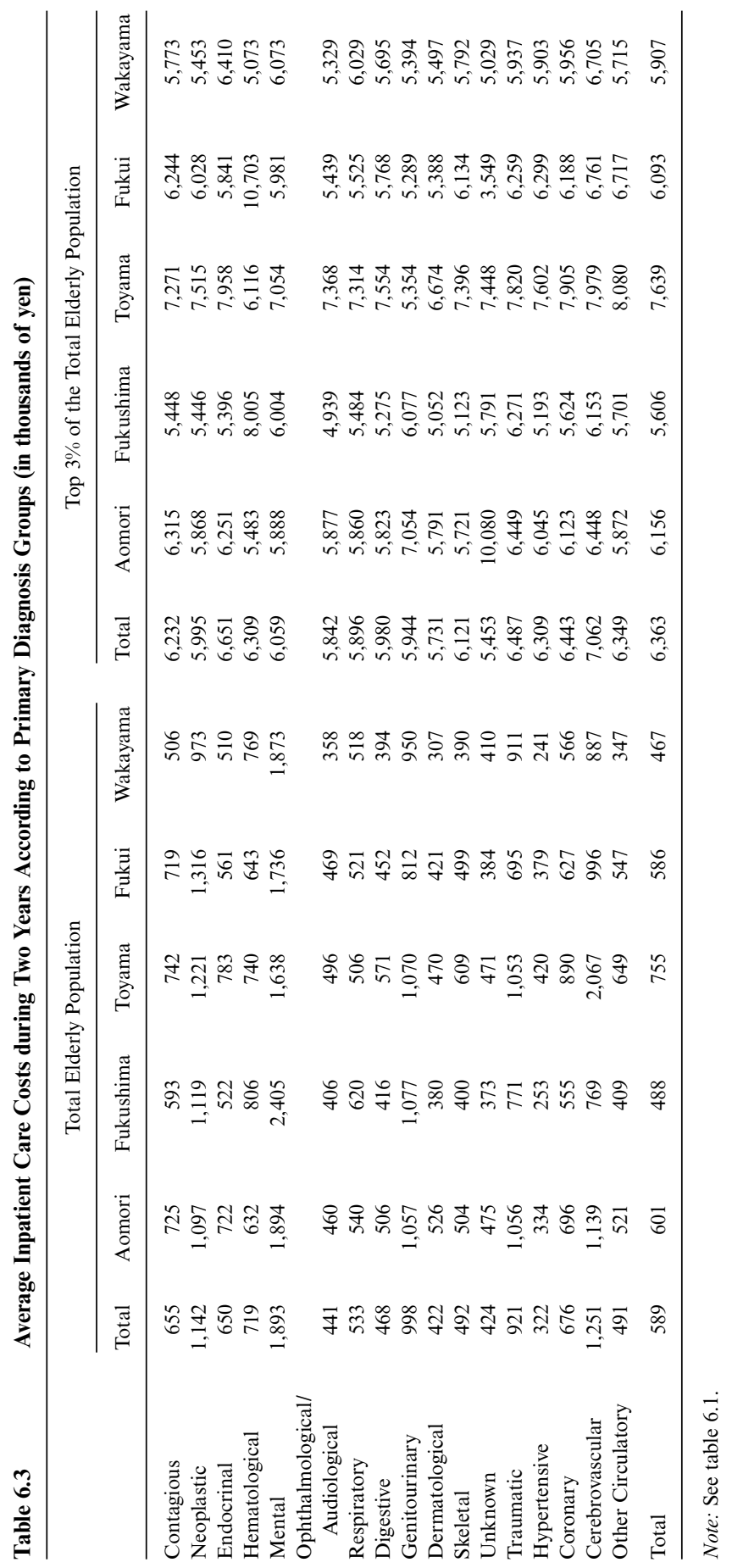




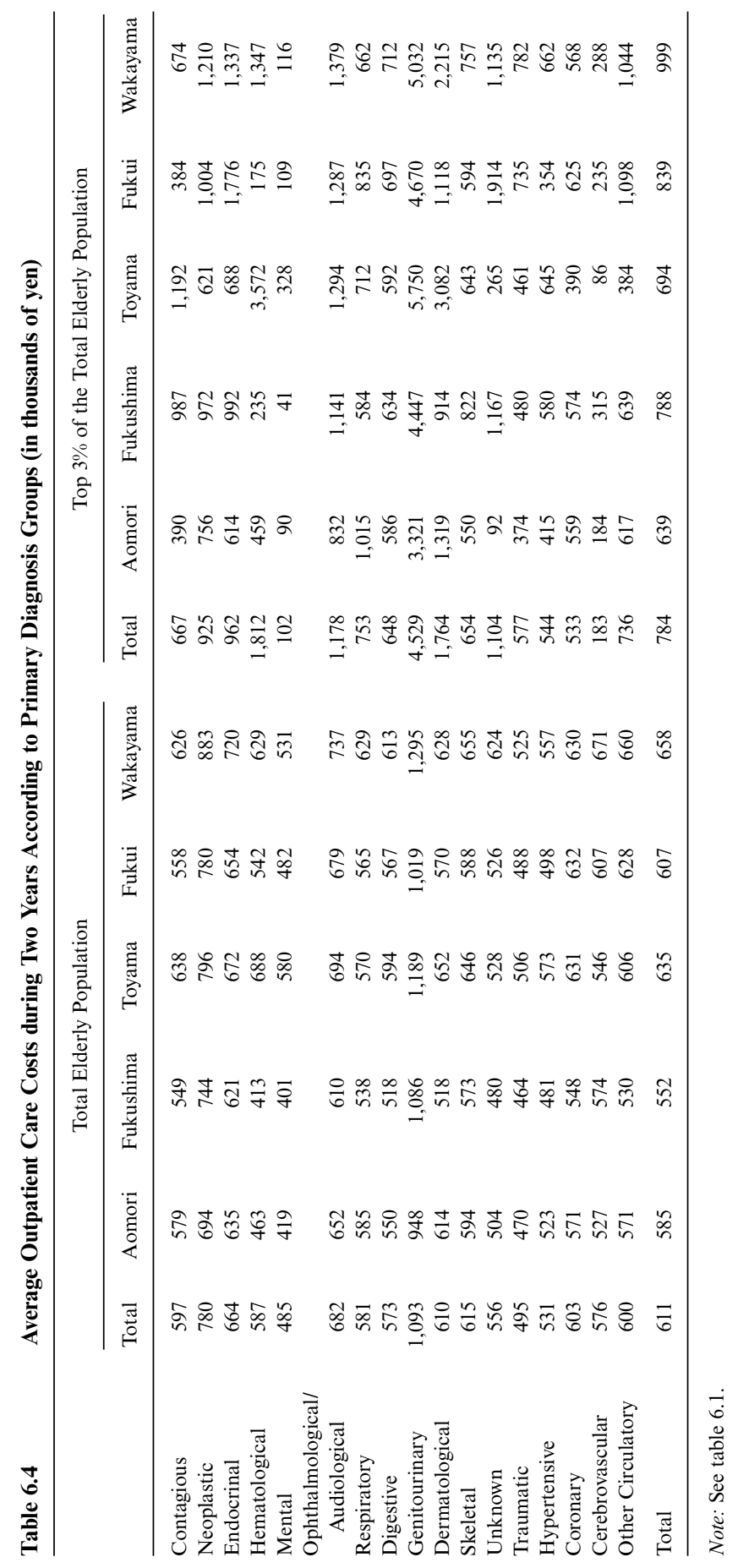




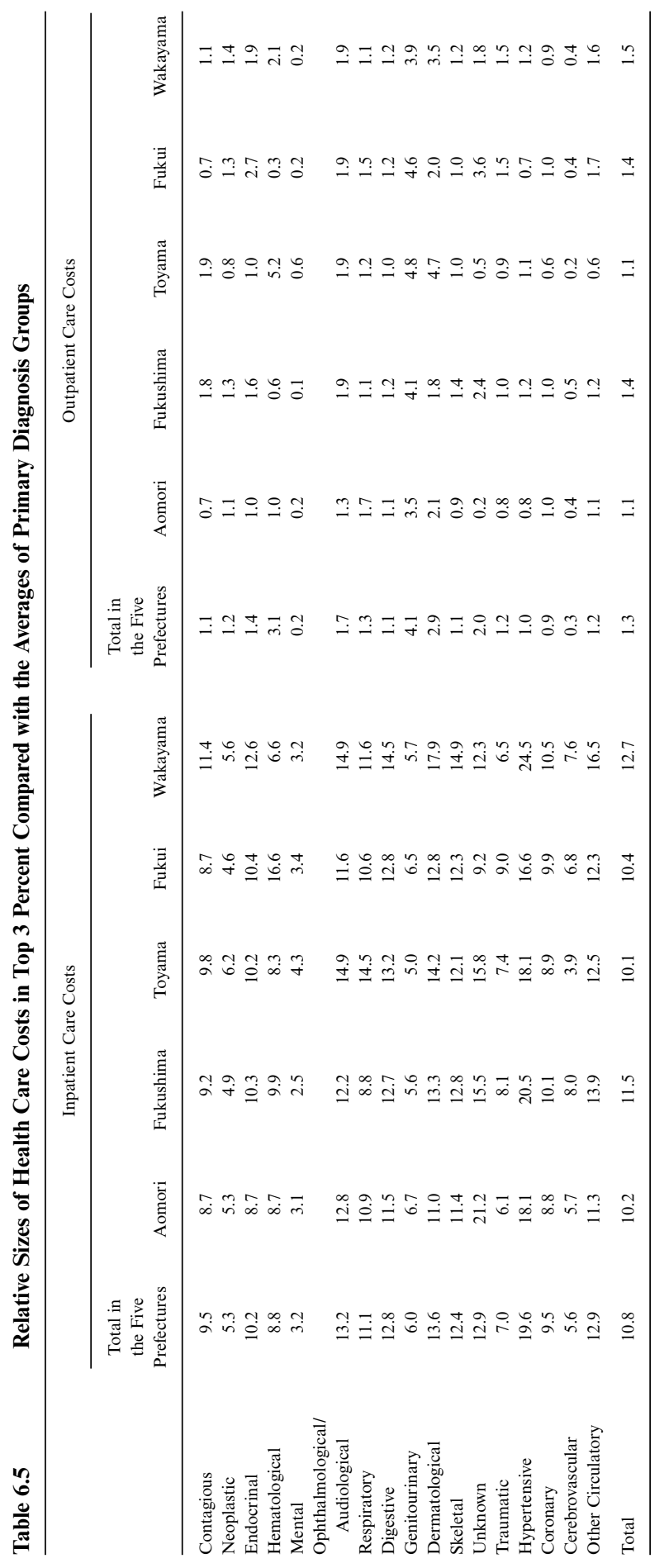




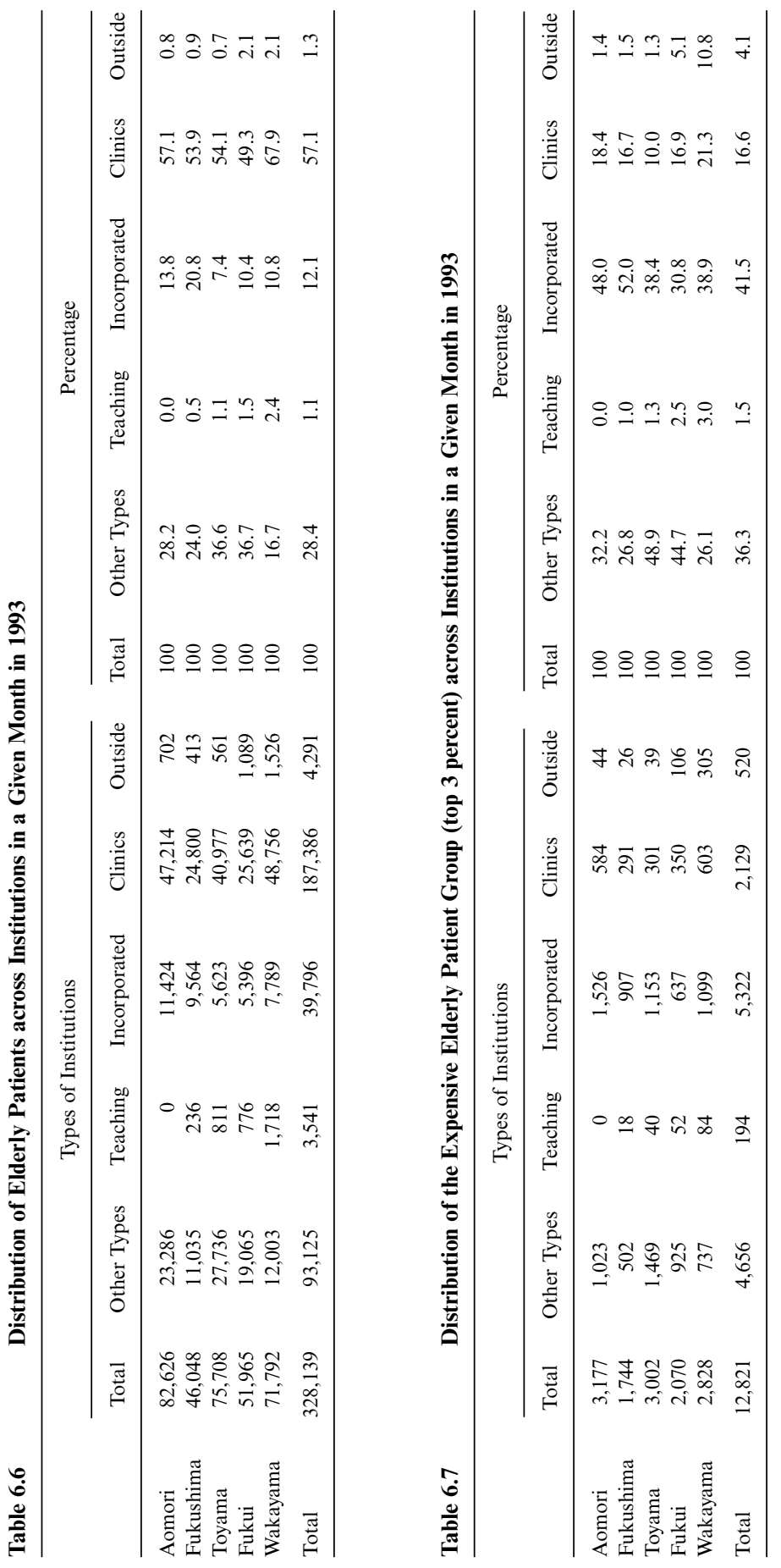


Probability of Belonging to the Expensive Elderly Patient Group (top 3 percent) in a Given Type of Institution

\begin{tabular}{lcccccr}
\hline & \multicolumn{6}{c}{ Percentages } \\
\cline { 2 - 7 } & Total & Other Types & Teaching & Incorporated & Clinics & Outside \\
\hline Aomori & 3.8 & 4.4 & & 13.4 & 1.2 & 6.3 \\
Fukushima & 3.8 & 4.5 & 7.6 & 9.5 & 1.2 & 6.3 \\
Toyama & 4.0 & 5.3 & 4.9 & 20.5 & 0.7 & 7.0 \\
Fukui & 4.0 & 4.9 & 6.7 & 11.8 & 1.4 & 9.7 \\
Wakayama & 3.9 & 6.1 & 4.9 & 14.1 & 1.2 & 20.0 \\
Total & 3.9 & 5.0 & 5.5 & 13.4 & 1.1 & 12.1 \\
\hline
\end{tabular}

vate hospitals rank at the top with about 13.4 percent, followed by out-ofprefecture hospitals (12.1 percent), teaching hospitals (5.5 percent), and the other types $(5.0$ percent). The patients at the clinics rank the lowest with only 1.1 percent probability, or one-fourth the average likelihood (3.9 percent).

The average health care costs of a patient treated for a certain primary diagnosis in a given type of institution during 1992-93 are given in table 6.9. In table 6.10, we have shown how many times more an expensive elderly patient costs than an average elderly patient for each type of institution in each prefecture. On the average, the ratio is 6.0, and except for clinics, the variation across different types of institutions is provided by the difference in the denominator (i.e., the cost of an average elderly), rather than the numerator (the cost of an expensive elderly). In the same table, the average health care cost of an expensive elderly patient in a given type of institution is given. Both of these cost measures can be subject to serious criticism, however, for two reasons. First, since we have nothing to impute the monthly expenditures to different institutions by Part A, we must rely on information supplied by Part B. In fact, we are imputing the costs incurred during a twenty-four-month period based on only one month of data. Second, in order to simplify the analysis, we impute all the health care costs of a patient incurred for all ailments and at all institutions to the institution where the patient is treated for the primary diagnosis. In spite of these shortcomings, we feel that the figures in table 6.9 are useful because, as we have seen, the major component of health care costs for the most expensive elderly is inpatient care, and many of these patients have been hospitalized for most of the twenty-four months studied.

Table 6.11 points to another source of concentration of health care expenditures among the elderly. Apparently, close to half (48.1 percent) of the revenues of the incorporated private hospitals come from the expensive elderly, or the top 3 percent of the elderly in the health care cost ranking, while other types of hospitals derive 25.4 percent of their revenue from 


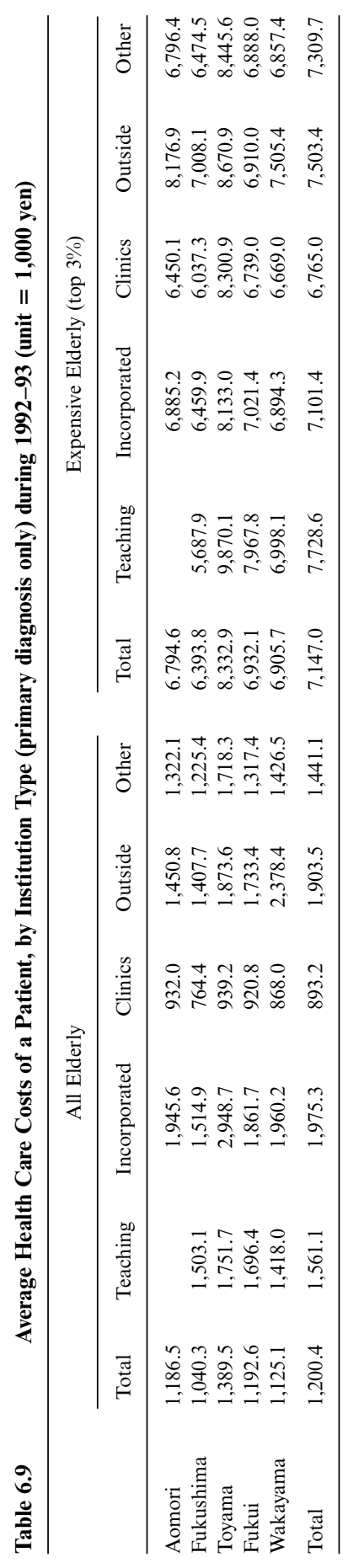


Table 6.10

Ratio of the Health Care Costs of the Expensive Elderly to Those of All Elderly, by Institution Type (primary diagnosis only)

\begin{tabular}{lcccccc}
\hline & Total & Teaching & Incorporated & Clinics & Outside & Other \\
\hline Aomori & 5.7 & & 3.5 & 6.9 & 5.6 & 5.1 \\
Fukushima & 6.1 & 3.8 & 4.3 & 7.9 & 5.0 & 5.3 \\
Toyama & 6.0 & 5.6 & 2.8 & 8.8 & 4.6 & 4.9 \\
Fukui & 5.8 & 4.7 & 3.8 & 7.3 & 4.0 & 5.2 \\
Wakayama & 6.1 & 4.9 & 3.5 & 7.7 & 3.2 & 4.8 \\
Total & 6.0 & 5.0 & 3.6 & 7.6 & 3.9 & 5.1 \\
\hline
\end{tabular}

Table 6.11

Revenue Share (\%) of the Expensive Elderly, by Institution Type (primary diagnosis only)

\begin{tabular}{lcccccc}
\hline & Total & Teaching & Incorporated & Clinics & Outside & Other \\
\hline Aomori & 22.0 & & 47.3 & 8.6 & 35.3 & 22.6 \\
Fukushima & 23.3 & 28.9 & 40.4 & 9.3 & 31.3 & 24.0 \\
Toyama & 23.8 & 27.8 & 56.6 & 6.5 & 32.2 & 26.0 \\
Fukui & 23.2 & 31.5 & 44.5 & 10.0 & 38.8 & 25.4 \\
Wakayama & 24.2 & 24.1 & 49.6 & 9.5 & 63.1 & 29.5 \\
Total & 23.3 & 27.1 & 48.1 & 8.6 & 47.8 & 25.4 \\
\hline
\end{tabular}

these patients. For clinics, the proportion is only 8.6 percent. Table 6.12 computes the average inpatient days of an elderly patient treated at an institution for what is considered his or her primary diagnosis, versus those of an expensive elderly patient. Average inpatient days for patients treated for all primary diagnoses in incorporated private hospitals are 116.8 days, or more than twice those of hospitals other than teaching and incorporated (55.1 days), and more than three times those of teaching hospitals (38.6 days). This bias seems to cut across all diagnoses and can easily push up the costs for those treated at incorporated hospitals relative to other institutions. It is interesting to see that even among the most expensive elderly patients, such a bias can still be observed across all diagnoses.

\subsection{Long-Term Inpatients and Regional Variations in the Distribution of Health Care Costs}

In the analysis presented in the previous section, several facts concerning the concentration of health care expenditure were revealed. In particular, the following facts strongly indicate that the presence of large numbers of inpatients may explain the increasing cost of health care for the elderly in Japan.

1. There is a significant concentration of health care costs for the elderly in Japan: The top 1 percent of patients account for 10 percent of total 


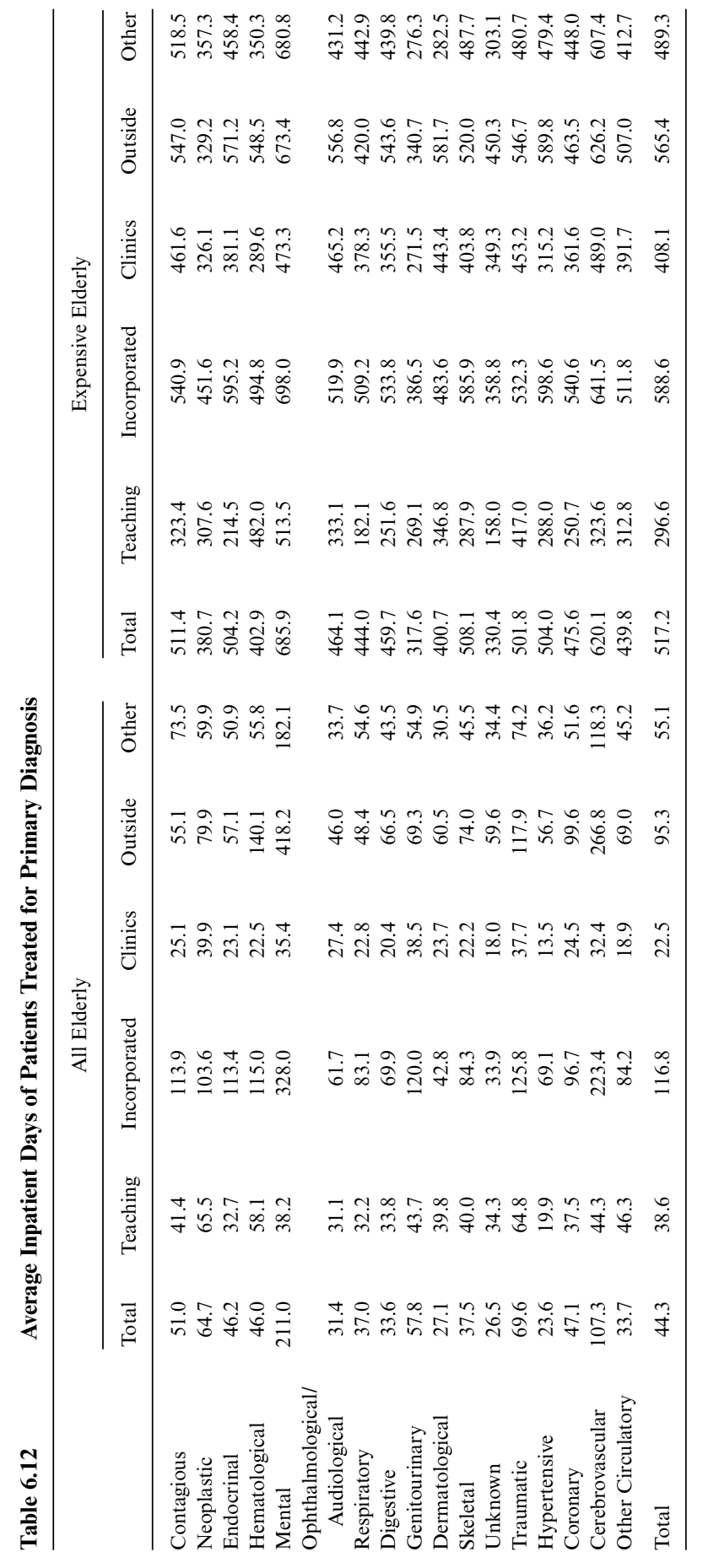


health care costs, and the top 10 percent account for a staggering 45 percent of these costs.

2. This concentration derives from inpatient care rather than outpatient care.

3. The concentration of spending on inpatient care appears to be attributable to the fact that the continuous length of stay of inpatients is high.

Most of the inpatients who stay in the hospital for a long time are elderly people who have difficulty living independently because they are left with physical disabilities after the completion of treatment during the acute stage of illness. Because there is a lack of alternative facilities for these elderly patients, this is called social hospitalization. In many cases, these long-term inpatients need long-term care, rather than actual medical treatment. How much of our valuable health care resources are taken up by these long-term inpatients whose need for medical treatment is limited? Is it perhaps possible that health care costs are higher in regions in which there are large numbers of long-term inpatients? Moreover, is it not true that increasing the supply of medical resources (the numbers of hospitals and hospital beds) will encourage long-term hospitalization, which in turn will generate higher health care costs?

In this section, we take the view that the existence of long-term hospitalization has a significant effect on the cost of health care for the elderly. Its effect on regional variations in health care expenditure, along with the effects that the regional supply of medical resources has on long-term hospitalization, are analyzed in this section from the point of view of the regional distribution of health care costs.

\subsubsection{Explanation of the Data Set and the Definition of Long-Term Hospitalization}

In the analysis of the concentration and continuation of health care expenditure discussed earlier, a new data set was created by combining two data sets, 1992 and 1993, with a common patient code among the insurance claims for health care for the elderly. Now we must obtain as much regional data as possible in order to analyze variations in regional health care costs. Thus, we discard the integrated two-year data in favor of the data for 1993 (twelve months) only. ${ }^{7}$ (The original data consist of individual health care microdata for elderly people from twelve municipalities, but it was possible to consolidate the data for two consecutive years in only five prefectures.)

7. The data set used in this analysis consist of health care insurance claim data for the elderly, excluding the following microdata: (a) those who became eligible for health care for the elderly in the course of 1993; (b) those who lost their eligibility through death or other reasons during 1993; and (c) those who had no municipality address code. Excluding these, there are 1,286,559 items of microdata for eleven prefectures ( 77 medical zones and 765 municipalities) in the data set. 
Next, we define long-term hospitalization as a period of three months (ninety days) or more. Inpatients staying for 180 days or more are, however, included when necessary. It should be noted that the number of long-term patients is probably underestimated because of the truncation of the data. ${ }^{8}$ We cannot single out those who have been hospitalized three months or more among the inpatients in the first two months or the last two months of our twelve-month longitudinal data set.

\subsubsection{Health Care Costs for Long-Term Inpatients}

In section 6.2, the longitudinal data on two consecutive years of health care showed that health care costs were concentrated among a relatively small number of elderly patients with lengthy periods of hospitalization. In this section, we study the relationship between concentration and longterm hospitalization, as revealed by the data. (Although the data cover a period of only one year, they are based on a large number of samples.)

Table 6.13 shows the proportion of long-term inpatients generating high health care costs, and the proportion of long-term inpatient health care costs attributable to these patients. The table shows that 82.9 percent of the top 1 percent of high-cost patients were long-term inpatients staying ninety days or more. The share peaked at 88.3 percent for the top 3 percent, then fell to 82.6 percent for the top 5 percent and to 55.6 percent for the top 10 percent. The majority of patients in the top 5 percent were long-term inpatients. From a health care cost viewpoint, we can see that although the top 1 percent of high-cost elderly patients accounted for 11.3 percent of the total health care costs for the elderly, 82.9 percent of that expenditure was attributable to long-term inpatients staying ninety days or more. Similarly, the top 5 percent accounted for 36.0 percent of the total health care costs, but 83.9 percent of that figure was attributable to longterm inpatients. Furthermore, the top 10 percent accounted for more than half (52.1 percent) of health care costs; of this amount, 67.7 percent was attributable to health care costs for long-term inpatients. So, from the oneyear health care cost data for 1993, we can also confirm that more than 80 percent of the top 5 percent of high-cost elderly patients' health care cost was attributable to long-term inpatients, and that these same patients accounted for more than 80 percent of the total expenditure on high-cost patients.

Next, we ascertain from table 6.14 the role of long-term hospitalization in the total cost of health care for the elderly. By looking at the health care cost shares in the three right-hand columns, we see that the cost of health

8. It was difficult to determine the effect of truncating data at both ends, but a Ministry of Health and Welfare patient survey showed, with respect to patients aged seventy or over, that 13.3 percent were hospitalized for three months or over, and 6.0 percent for six months or over. By contrast, in our data set the incidence of inpatients hospitalized for three months (90 days) or over was 5.8 percent, and for six months (180 days) or over, 3.4 percent. 


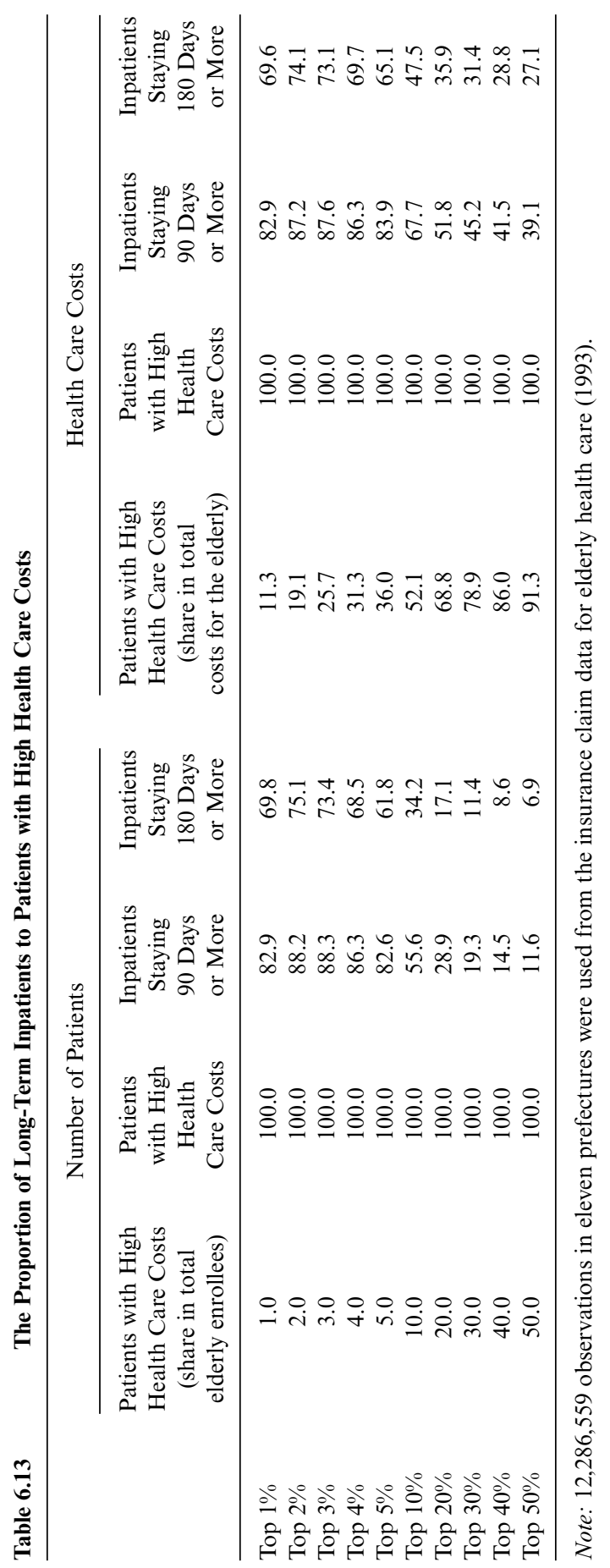




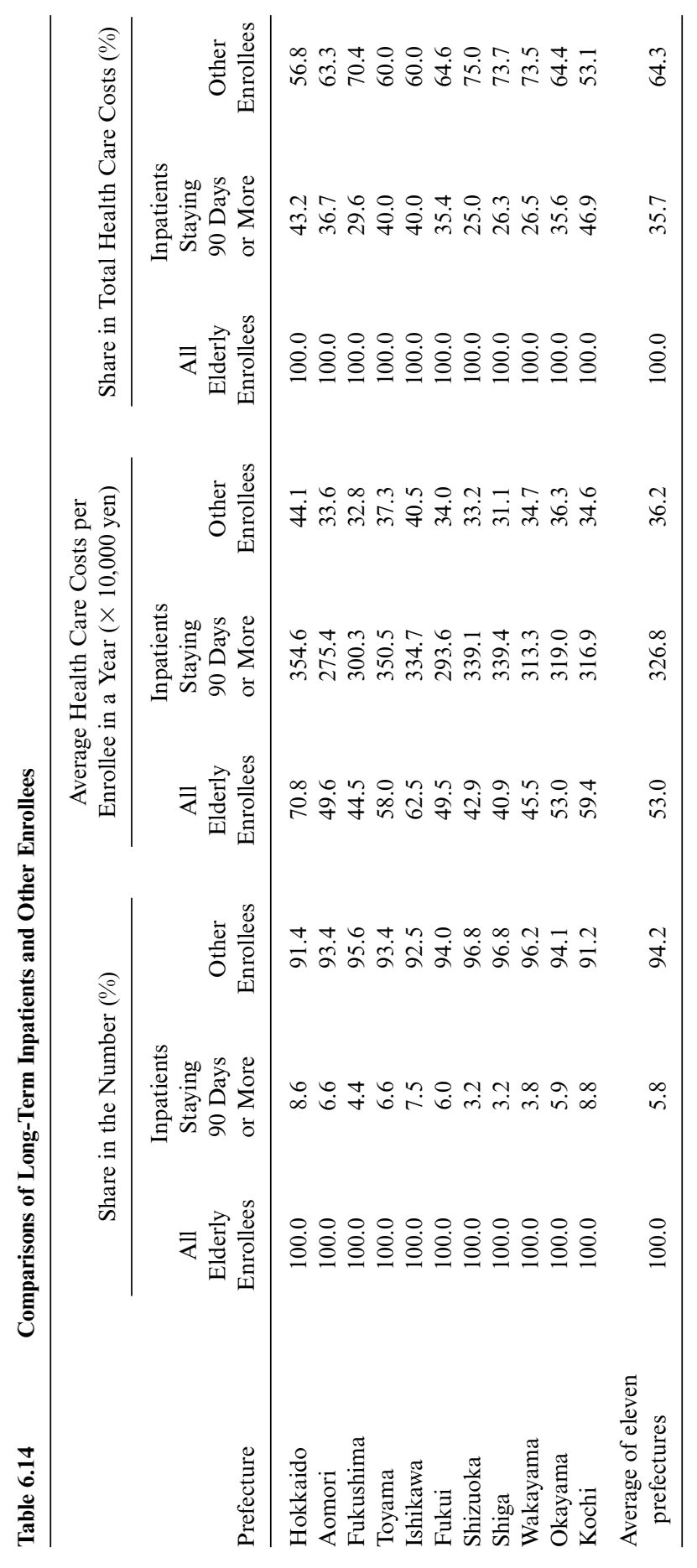


care for long-term inpatients staying for ninety days or more accounts for 35.7 percent of the total cost of health care for the elderly. Thus, more than one-third of the cost of health care is spent on long-term inpatients who need comparatively little active medical treatment but much more long-term caretaking. Incidentally, there is a wide variation in these ratios from one prefecture to another. The cost of long-term inpatient health care accounts for more than 40 percent (the highest figures) in Kochi prefecture (46.9 percent) and Hokkaido (43.2 percent). The ratio is much smaller in Shizuoka prefecture (25.0 percent).

Why are there differences at a prefectural level in the share of health care costs attributable to long-term inpatients? In the 11 prefectures, the average cost of health care for a long-term inpatient is 3,268,000 yen, nine times higher than the figure of 362,000 yen for other elderly patients (columns [8] and [9] in the table). However, prefectural differences are surprisingly small and the difference between the figures is always less than 30 percent (2,754,000 yen in Aomori prefecture and 3,546,000 yen in Hokkaido). If this cannot be explained by the difference in per-patient health care costs, then the main reason for prefectural variations in the percentage share of health care costs for long-term inpatients (between 25 percent and 46.9 percent) must be the difference in numbers of long-term inpatients: In other words, the difference in the incidence of long-term hospitalization.

If we look at the percentage of long-term inpatients in the total of elderly patients (column [2]), although the average is 5.8 percent, the differences among prefectures vary widely between the high figures in Kochi (8.8 percent) and Hokkaido (8.6 percent) and the low ones in Shizuoka and Shiga (each at 3.2 percent). In other words, the figures confirm that the total long-term inpatient health care costs are high in prefectures with a large proportion of long-term inpatients.

Furthermore, in prefectures where the ratio of long-term inpatients is high, the average health care cost per elderly patient (column [4]) is also high. The scatter diagram in figure 6.5 confirms the relationship between the ratio of long-term inpatients and average health care costs. There is a strong positive correlation between the two, and the larger the number of long-term inpatients, the higher the average health care costs for the elderly become. From this, the possibility emerges that among the many reasons for the prefectural variations in health care costs for the elderly, the incidence of long-term hospitalization is a particularly valid one.

\subsubsection{Long-Term Inpatients and the Distribution of Health Care Costs}

We have now established that there are two effects of the incidence of long-term inpatients' staying ninety days or more. One is that the average health care cost rises significantly; the other is that regional variations in health care costs increase in direct proportion to the number of long-term inpatients. We examine this in more detail below. 


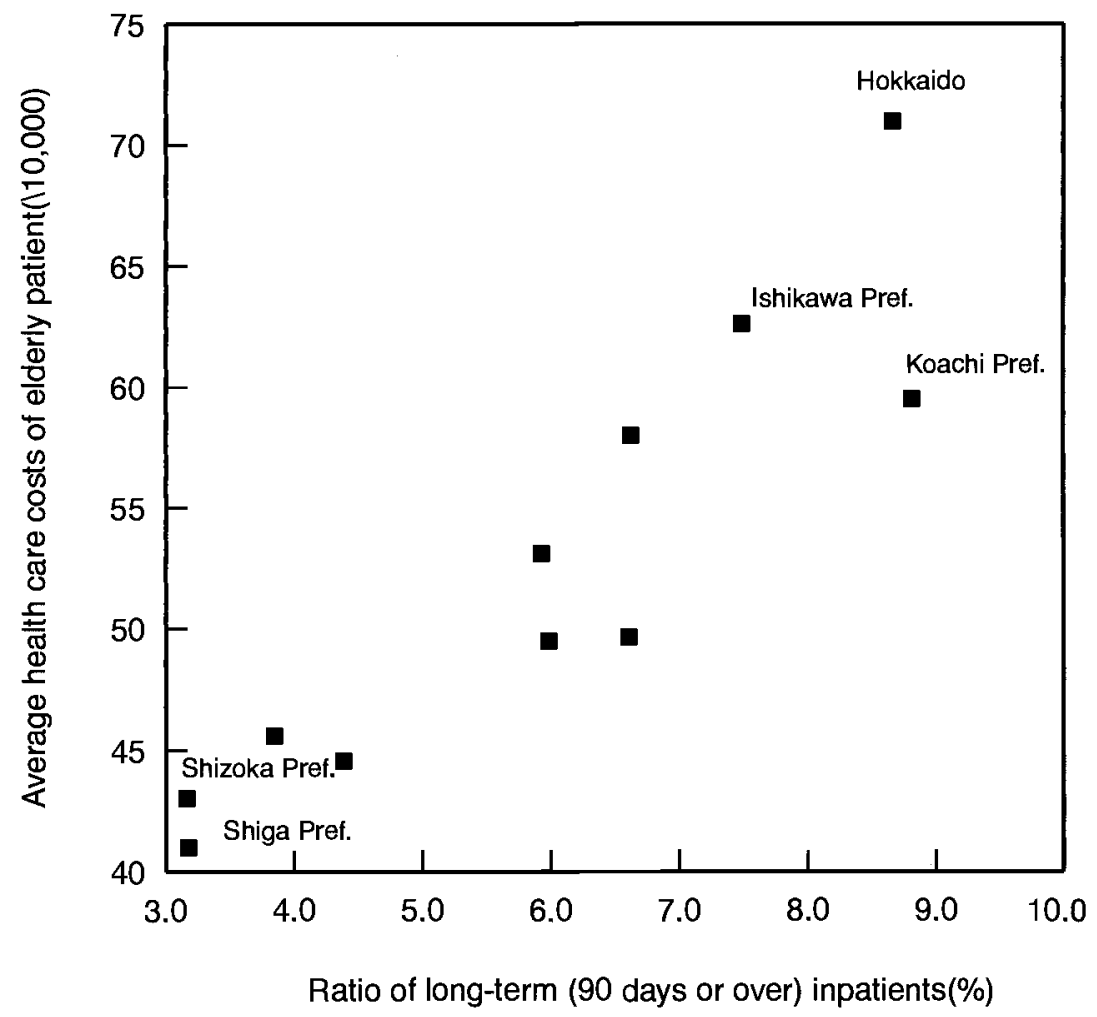

Fig. 6.5 Ratio of long-term inpatients to average health care cost of elderly patients (per prefecture)

First, however, let us consider what kind of regional medical units exist. In many cases, when discussing health care cost issues, a prefecture is taken as the unit of discussion. However, in terms of medical resources such as hospitals and hospital beds, there are many instances in which a medical zone is the unit of discussion. The number of medical zones depends to some extent on the area of the prefecture, but a prefecture is generally divided into several zones. From the viewpoint of a patient covered by National Health Insurance, the municipality should be considered the unit. We consider all three units in our analysis.

To establish the extent to which variations in health care costs can be increased by the incidence of long-term hospitalization, we compare the values of the total number of elderly people eligible for health care, including long-term inpatients, and the number of those eligible for health care, excluding long-term inpatients (table 6.15). The first and second rows show the values for microdata, whereas the third and fourth rows give the values at a prefectural level. The average prefectural health care cost per elderly 


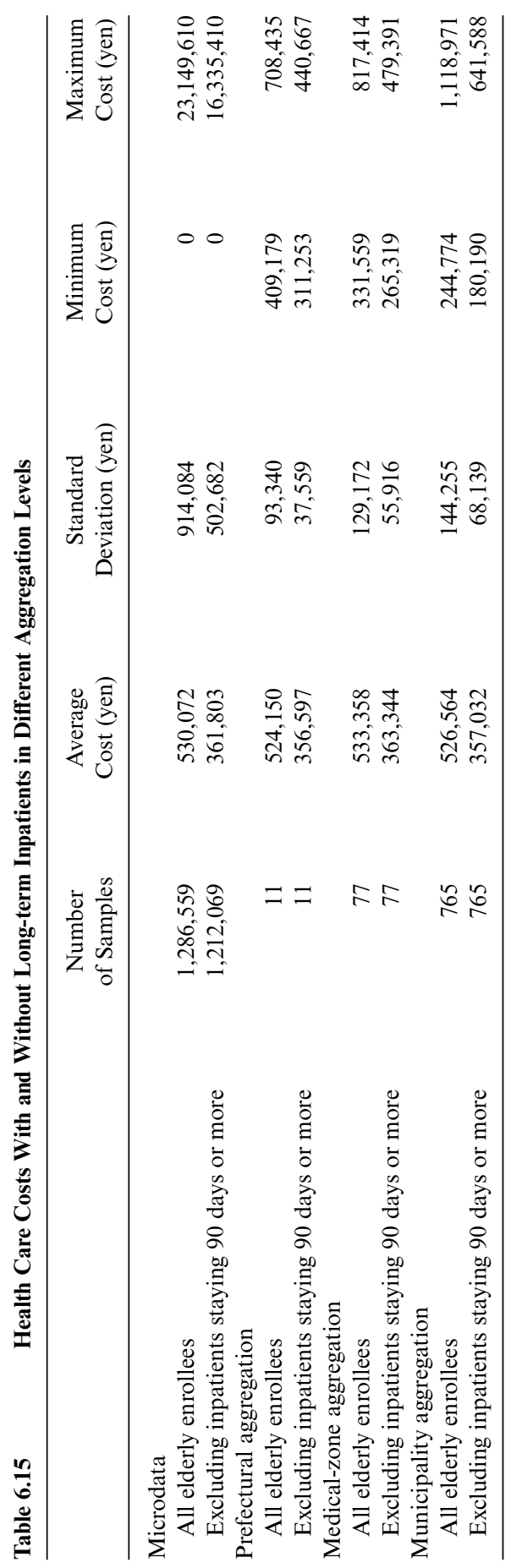


patient ranges from about 409,000 yen to about 708,000 yen, producing a standard deviation around 93,000 yen. If the long-term inpatients are excluded, however, the prefectural averages range from about 311,000 to about 441,000 yen, bringing the standard deviation down to around 38,000 yen. Thus, variations in health care costs for the elderly are relatively small when long-term hospitalization is excluded. If the element of long-term inpatient care could somehow be removed from the calculation of health care costs, the prefectural variations in such costs would automatically decrease.

Health care costs vary more widely between medical zones (rows [5] and [6] of the table) than between prefectures (rows [3] and [4]) and even more widely between municipalities (rows [7] and [8]). Our data set, which covers seventy-seven medical zones, shows that their average medical costs range between about 332,000 and 817,000 yen, the ratio of the maximum to the minimum being $2.5: 1$. If the element of long-term inpatient care is excluded, however, the costs range from about 265,000 to 479,000 yen, and the ratio falls to $1.8: 1$. For municipalities, the costs, including those of long-term inpatient care, range between about 245,000 and 1,119,000 yen, and the ratio rises to 4.6:1. Furthermore, this variation can be reduced to about 180,000 to 642,000 yen by excluding the cost of long-term inpatient care.

Thus, we can see that the distribution of average health care costs in medical zones and municipalities can be leveled to some extent by excluding expenditures on long-term inpatient care. To illustrate this visually, figures 6.6 and 6.7 show the changes in the frequency distribution. The upper graph shows the overall distribution including long-term hospitalization, and the lower graph shows the distribution when long-term hospitalization is excluded. In the upper graph, the distribution shows the right side (high-cost portion) extending farther because there are regions with high medical expenditures. It resembles a normal distribution more closely in the lower graph. Incidentally, the horizontal axis represents the annual health care costs in yen, and the vertical axis represents the relative frequency (percent).

\subsubsection{Long-Term Inpatients and the Availability of Medical Resources}

It is evident that long-term hospitalization not only pushes up the cost of health care for the elderly, but also that, because it distorts the distribution of health care costs, it influences regional variations in those costs. One of the reasons for these regional variations is that some regions have large numbers of long-term patients, while others have relatively few.

What are the reasons for these differing demands for long-term inpatient care? Starting from the premise that a market for health care for the elderly develops in each region, the elderly are consumers; hospitals, clinics, and other health care institutions are suppliers. (In Japan, it is more appro- 

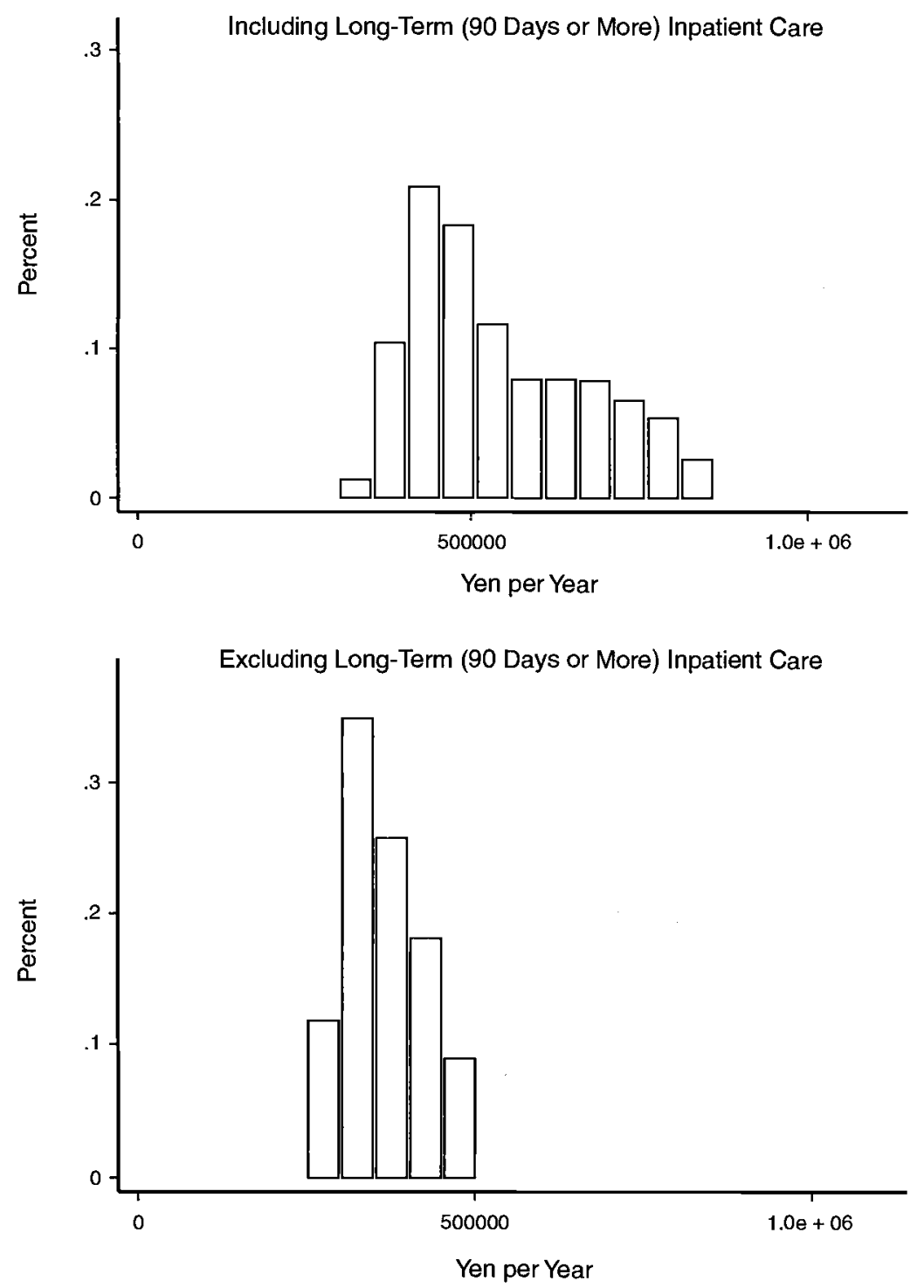

Fig. 6.6 Frequency distribution of average health care cost in fiscal 1993, by zone

priate to describe health care institutions, rather than individual doctors, as economic entities.)

Elderly consumers create a demand for health care as their health declines, but the extent of that demand is determined by such elements as age, sex, family circumstances, and so on. Since it is believed that the level of medical treatment demanded by an individual is a function of that person's financial status, the demand for health care may be considered to 

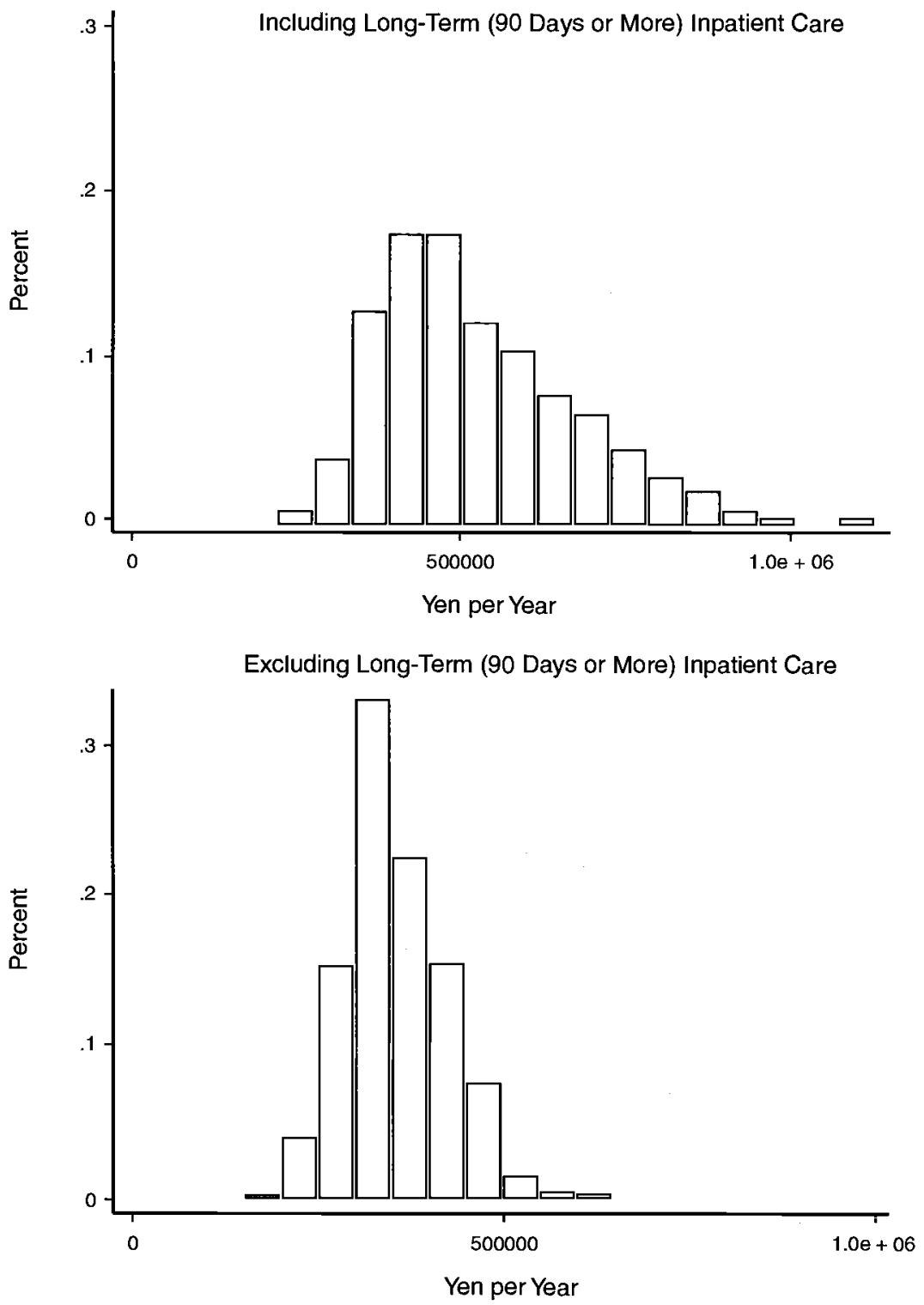

Fig. 6.7 Frequency distribution of average health care cost in fiscal 1993, by municipality

be an increasing function of the general level of income. However, if we consider that the possibility of declining health increases as the level of income diminishes, then the demand for health care can also be regarded as a decreasing function of the general level of income.

Health care institutions, on the other hand, provide services on a fixed- 
price basis. The government can restrict increases in the numbers of beds, but under the fee-for-service system, the institutions can provide unrestricted health care service to their patients. In regions where there are larger health care resources (numbers of doctors, health care institutions, beds) per capita, health care institutions have greater incentive to provide health care services in order to make a profit (supplier-induced demand hypothesis [Nishimura 1987]). The levels of incentive vary as a function not only of the availability of health care resources, but also of the degree of concentration.

According to American interpretations, the likelihood of oversupply diminishes as concentration decreases and the market becomes more competitive. This presupposes that prices are free to fluctuate in response to demand, a situation that does not necessarily apply in Japan. In fact, the opposite could be said to apply in Japan, where prices are fixed and the patient's own financial contribution is low. In other words, there is a tendency toward an oversupply with respect to health care services in regions in which there are of large numbers of medium-sized hospitals.

What about the demand for long-term hospitalization? If this demand is almost the same as that for health care, then the situation is almost the same as that of general health care services, in that demand is affected by individual and family circumstances. However, if we believe that patients with larger incomes are more likely to purchase health care services other than hospitalization, then the demand for long-term hospitalization should decrease as the level of patient income increases.

As to the provision of long-term hospitalization services, there is still a significant incentive for hospitals to accept elderly long-term inpatients, although the profit motive is considered to have diminished after Japan's Ministry of Health and Welfare introduced a system under which hospitalization charges decrease progressively as the period of hospitalization increases.

Recently, the fixed-price system was introduced. Under this system, a certain amount of remuneration is paid without the prescription of medicine or injections, if the capability of providing care is enhanced. Hence, accepting long-term inpatients leads to a stable operational basis for health care institutions. We can assume that health care institutions have an incentive to provide long-term hospitalization services to patients whose treatment at the acute stage has been completed.

What if the demand for long-term hospitalization and for caretaking are identical? The much higher demand than supply of caretaking leads to the rationing of services, rather than to the unreasonable creation of demand by health care institutions.

Whichever hypothesis is correct may be determined by taking into account the contribution by special nursing homes for the elderly - alternative institutions specializing in long-term care. If the levels of long-term 
hospitalization are lower in the regions with more of these special nursing homes, the first hypothesis applies. If the number of long-term hospitalizations remains the same when the number of special nursing homes increases somewhat, then the latter hypothesis that demand for caretaking exceeds the supply (total of the number of beds in health care institutions and special nursing home for the elderly) is valid.

\subsubsection{Estimation of the Probability of Long-Term Hospitalization}

The aim of this section is to determine whether the market hypothesis matches the reality, and to measure the extent to which the supply of health care influences the incidence of long-term hospitalization.

In the measurement, whether each elderly patient is (1) or is not (0) a long-term inpatient is defined as a dependent variable. Demand-side factors (patient attributes, income, etc.) and supply-side factors (density of health care resources, degree of market concentration, density of alternative care facilities, etc.), which were examined in the previous section, were defined as explanatory variables to explain the probability of long-term hospitalization.

Therefore, we use the estimation formula

$Y=f$ (Patient Attributes, Income, Density of Health Care Resources,

Degree of Market Concentration, Density of Alternative Care Facilities),

where

$$
Y=1 \text { (Long-term Inpatient) and } 0 \text { (Others). }
$$

In formulas such as this in which the dependent variable is $0 / 1$, the logit model and the probit model typically are employed for estimation. Since it is easier to evaluate the estimation parameters, the logit model is used here.

Table 6.16 summarizes the variables used in the estimation. The dummy for long-term hospitalization, which is the dependent variable, will be 0 or 1 , and the average value is 5.79 percent. The individual attributes used as demand factors are an average age of 77 and a male/female ratio of 40 percent to 60 percent. The share of subscribers to health insurance other than the National Health Insurance is 19.6 percent. Income is an individual attribute, but since individual income figures were not available, the average taxable income of the region (approximately 1,200,000 yen) was used as an alternative.

With regard to supply variables, three types of aggregate value were established for each market unit (the scale of the region). To indicate the density of health care resources, we used bed density (per capita number of beds) was used (the number of beds being the total in both clinics and hospitals). Doctor density is also frequently used as a variable, but in the case of long-term hospitalization, inpatient health care resources-partic- 
Table 6.16 Statistical Description of Variables

\begin{tabular}{|c|c|c|c|c|}
\hline Variables & Average & $\begin{array}{l}\text { Standard } \\
\text { Deviation }\end{array}$ & Minimum & Maximum \\
\hline \multicolumn{5}{|l|}{ Microdata } \\
\hline \multicolumn{5}{|l|}{ Long-term hospitalization } \\
\hline Dummy ${ }^{\mathrm{a}}$ & 0.0579 & 0.2336 & 0 & 1 \\
\hline Age & 77.11 & 5.72 & 65 & 110 \\
\hline Male dummy & 0.404 & 0.491 & 0 & 1 \\
\hline \multicolumn{5}{|l|}{ Non-National Health } \\
\hline Insurance dummy & 0.196 & 0.397 & 0 & 1 \\
\hline \multicolumn{5}{|l|}{ Prefectural aggregation data } \\
\hline Number of beds ${ }^{b}$ & 110.1 & 23.8 & 75.0 & 146.8 \\
\hline Concentration index of beds ${ }^{c}$ & 0.011 & 0.005 & 0.003 & 0.023 \\
\hline $\begin{array}{l}\text { Capacity of nursing homes for } \\
\text { the elderly }\end{array}$ & 158.2 & 53.8 & 102.5 & 259.7 \\
\hline Taxable income $e^{\mathrm{e}}$ & $1,261.2$ & 198.0 & 889.5 & $1,530.5$ \\
\hline \multicolumn{5}{|l|}{ Medical-zone aggregation data } \\
\hline Number of beds ${ }^{b}$ & 109.6 & 34.9 & 10.7 & 236.8 \\
\hline Concentration index of beds ${ }^{\mathrm{c}}$ & 0.070 & 0.065 & 0.020 & 0.554 \\
\hline $\begin{array}{l}\text { Capacity of nursing homes for } \\
\text { the elderly }\end{array}$ & 158.7 & 71.9 & 30.6 & 597.3 \\
\hline Taxable income $e^{e}$ & $1,246.2$ & 229.6 & 728.8 & $1,614.2$ \\
\hline \multicolumn{5}{|l|}{ Municipality aggregation data } \\
\hline Number of beds ${ }^{b}$ & 106.4 & 83.1 & 0 & $2,670.8$ \\
\hline Concentration index of beds ${ }^{c}$ & 0.336 & 0.333 & 0 & 1 \\
\hline $\begin{array}{l}\text { Capacity of nursing homes for } \\
\text { the elderly }\end{array}$ & 160.4 & 165.8 & 0 & $2,126.0$ \\
\hline Taxable income $e^{\mathrm{e}}$ & $1,232.4$ & 258.2 & 573.5 & $1,886.2$ \\
\hline
\end{tabular}

${ }^{\text {a }}$ Length of stay in hospitals during the year (dummy variable: 180 or more $=1$, less than $180=0$ ).

${ }^{\mathrm{b}}$ Number of hospital beds per 10,000 people.

${ }^{\mathrm{c}}$ Herfindahl index.

${ }^{\mathrm{d} C a p a c i t y ~ p e r ~ 10,000 ~ e l d e r l y ~ p a t i e n t s ~ a g e d ~ s i x t y-f i v e ~ o r ~ a b o v e . ~}$

${ }^{\mathrm{e}}$ Taxable income per capita (in thousands of yen).

ularly bed capacity - are considered to be more important. The Herfindahl index ${ }^{9}$ for the number of beds is used to measure the degree of market concentration. The value of this index is between 0 and 1 ; the larger the figure, the higher the degree of concentration. The degree of bed density decreases as the market expands. At an average value, it gets higher in the order of prefectures, medical zones, and municipalities. The capacity of special nursing homes for the elderly is included as an alternative longterm hospitalization facility.

Table 6.17 shows the results. Number of beds, degrees of bed concentration, and capacity of special nursing homes for the elderly have significant

9. The Herfindahl index, which is defined by the following equation, indicates the degree of concentration or monopoly of suppliers in a market: $H=\sum_{i=1}^{n}\left[X_{i} / \sum_{i=1}^{n} X_{i}\right]^{2}$. In this analysis, $X_{i}$ is the number of patients in $i$-th hospital in the given municipality. 


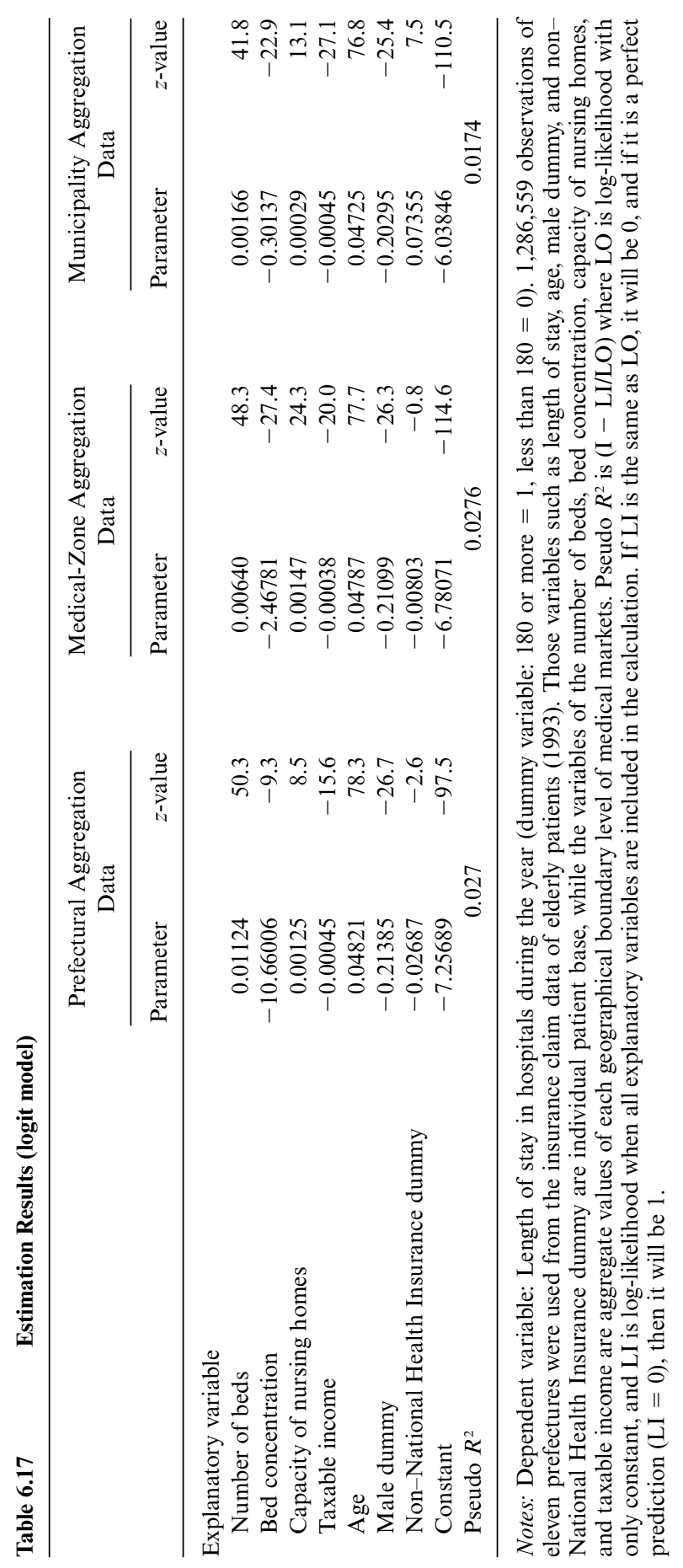


explanatory power. The positive number of beds suggests that the larger the number of beds per capita, the higher the probability of long-term hospitalization. The negative degree of bed concentration shows that the probability of long-term hospitalization decreases as the degree of concentration gets higher. The positive capacity of nursing homes indicates that the probability of long-term hospitalization is higher in regions with more special nursing homes for the elderly. The hypothesis that the supply of long-term care services by special nursing homes for the elderly serves as an alternative to long-term hospitalization cannot be proved. As was mentioned earlier, one interpretation of this is that in the current situation, in which there is insufficient provision of specialist long-term care facilities such as nursing homes, both they and other health care facilities are providing long-term care services in regions where the demand for care is particularly high.

The estimation was based on the premise that there were three types of health care market (prefectures, medical zones, and municipalities). Overall statistical significance is highest in terms of the number of beds, degree of concentration, and capacity of special nursing homes for the elderly, in the medical zone. We conclude that the market for long-term hospitalization services is likely formed within medical zones.

Next, we evaluate the degree of effects by estimated parameters on the dependent variables using average values. ${ }^{10}$ At the prefectural level, when the number of beds per 10,000 population is increased by one, the probability of average long-term hospitalization ( 5.79 percent) rises by 0.06 percent. Thus, a 10 percent increase in the bed density causes a 0.7 percent rise in the probability. The effect appears to be small. However, when this relationship is assumed to be constant, difference in bed density among prefectures (75.0 - 146.8 beds) may produce a maximum of 4.4 percent difference in the probability of the elderly's long-term hospitalization. As figure 6.4 shows, the effect of an increase in the number of long-term inpatients on health care costs is large, so the effects of the bed density cannot be ignored. A 10 percent change in bed density at the medical-zone level causes the probability of long-term hospitalization to increase by 0.38 percent, which is lower than at the prefectural level. However, since the variance in bed density is much larger (between 10.7 and 236.8) at the medicalzone level, the difference in bed density may produce a maximum of 7.9 percent difference in the probability of long-term hospitalization. The difference in the probability at the municipal level may reach as high as 24.2 percent. ${ }^{11}$

10. The changes in the probability $P_{i}$ for the dependent variable $Y$ to become 1 when the explanatory variable $x_{j}$ changes is given by the formula $\partial P_{i} / \partial x_{i j}=\beta_{j} P_{i}\left(1-P_{i}\right)$, where $i$ and $j$ are adscripts meaning observation and explanatory variables, respectively.

11. Since, in the logit model, the assessment of a parameter that is an average value cannot be applied at a point where it is far from the average value, the above applications to maximum and minimum values should be considered only as references. 
When we look at the demand factors, income, age, and sex are all highly significant, except in the case of the non-National Health Insurance dummy, which has a low statistical significance. Moreover, the scale of the parameters at prefecture, medical zone, and municipality levels is stable. When trial estimations are made of the degree of influence of each variable, income has a clear negative effect, as expected, and a 100,000-yen increase in income reduces the long-term hospitalization probability by 0.2 percent. As for the effect of age, in an average sample age of seventyseven, for each age increment of one year the long-term hospitalization probability increases by 0.26 percent. The probability of long-term hospitalization is 0.6 percent higher for males than for females.

From these estimation results, the following four points are evident:

1. Demand for long-term hospitalization (or long-term care service) forms a market within medical zones.

2. Long-term hospitalization increases when the number of beds per capita increases (when the number of beds increases by 10 percent at medical-zone level, the long-term hospitalization probability increases by 0.38 percent).

3. In areas with special large-capacity nursing homes for the elderly, the long-term hospitalization probability was also high.

4. As the long-term hospitalization probability increased with age $(0.26$ percent increase per year), the increase in the number of long-term inpatients reflected an increase in the numbers of late-stage elderly patients.

\subsection{Conclusions}

We have learned that more than 80 percent of high-cost elderly patients (top 5 percent) are long-term inpatients hospitalized for ninety days or more. One-third of the cost of health care for the elderly is devoted to such long-term hospitalization. Consequently, the difference in the incidence of long-term hospitalization is one of the main reasons for regional variations in health care costs. We also know that the probability of an elderly patient's becoming a long-term inpatient is high in areas where the number of beds per capita is high, and that the long-term hospitalization probability is high in areas where the capacity of special nursing homes for the elderly is large.

We conclude, therefore, that long-term hospitalization or care-oriented services explain the major part (over 80 percent) of high-cost elderly patients in the health care system in Japan, rather than any unforeseeable phenomena such as accidents, fatal diseases, or serious surgical operations. The health care costs associated with long-term hospitalization account for one-third of the total cost of health care for the elderly. It is interesting to note that expenditure on long-term care by Medicaid, the public health care insurance system for the elderly in the United States, 
accounted for 33 percent of the total expenditure in 1994, a figure almost identical to our own measurement. Because home-care charges are included in Medicaid's long-term care figures, we cannot compare the two directly, but it can be said that the cost of long-term care is very high in both countries. The important point here is that in the United States, longterm care is considered quite separately from acute care. In Japan, the same high level of human resources used at the acute stage is also employed in long-term care. It is apparent that this leads to a very considerable demand on such resources. It is important to define clearly the "care" aspect of health care, and to ensure that there is a "care" service in place to provide it.

Finally, there are more long-term hospitalizations in areas in which there are large numbers of beds in health care facilities, as well as in areas where the capacity of special nursing homes, which are formal long-term care service providers for the elderly, is large. This leads us to conclude that a care-service provision system, which combines health care facilities and special nursing homes for the elderly, exists in areas where there is a large demand for long-term hospitalization (that is, demand for long-term care). In order to establish whether rationing is occurring - because supply cannot catch up with a rapidly increasing care demand-a further detailed analysis, taking into consideration other care facilities and differences in family circumstances, is needed.

\section{References}

Gornick, M., A. McMillan, and J. Lubitz. 1993. A longitudinal perspective on patterns of Medicare payments. Health Affairs 12 (2): 140-50.

Niki, Ryu. 1990. Empirical study on health care in modern Japan [in Japanese]. Tokyo: Igaku Shoin.

Nishimura, Shuzo. 1987. Economic analysis of health care (in Japanese). Tokyo: Toyokeizai Shinposha.

Ogura, Seiritsu, and Reiko Suzuki. 1997. Physician supply and the demand for health care. Paper presented at Japan Econometric Society Meetings, 14-15 September, Tokyo. 